\title{
A INSOLÊNCIA DAS OPERADORAS DE TELEFONIA: PRÁTICAS ABUSIVAS CONTRA 0 CONSUMIDOR
}

\author{
Érica da Silva Poisler, Fábio Ferreira Morong
}

Universidade do Oeste Paulista - UNOESTE, Curso em Direito, Presidente Prudente, SP, E-mail: ericapoisler@gmail.com

\begin{abstract}
RESUMO:
Este artigo objetiva apresentar, de forma dialético-dedutiva e com exemplos de situações cotidianas, as práticas abusivas das operadoras de telefonia no Brasil, que se aproveitam da vulnerabilidade, da falta de tempo e do desconhecimento do consumidor, levando-o a erro com suas publicidades enganosas ou disfarçadas de notificações de serviços, e o agravante: com o bloqueio de Internet considerado abusivo pela justiça brasileira. O presente estudo mostra o drama vivido por milhares de brasileiros que estão sujeitos aos mandos e desmandos das operadoras de telefonia que atuam no país, e a necessidade de maior clareza na legislação brasileira referente à franquia diária de uso de dados e pacotes de velocidade (Internet), tanto na modalidade fixa como na móvel, por meio de normas esclarecedoras, combinadas com maior rigor das autoridades competentes a respeito da insolência das operadoras de telefonia.
\end{abstract}

Palavras-chave: telefonia, operadoras, consumidor, celular, Internet.

\section{THE INSOLENCE OF TELEPHONY OPERATORS: UNFAIR PRACTICES AGAINST THE CONSUMER}

\begin{abstract}
:
This article presents, dialectically-deductive and with examples of everyday situations, the abusive practices of telephony operators in Brazil, taking advantage of the vulnerability, the lack of time and consumer ignorance, leading him to mistake with their deceptive publicities or disguised service notifications, and the aggravating: with Internet blocking considered abusive by the Brazilian courts. This present study shows the drama lived by thousands of Brazilians who are subject to the mands and excesses of telephony operators operating in the country, and the necessity for greater clarity in the brazilian legislation on the daily standards, combined with tightening of the competent authorities about the insolence of telephone companies.
\end{abstract}

Keywords: telephony, operators, consumer, mobile, Internet. 


\section{INTRODUÇÃO}

A sociedade, diante da insolência das operadoras de telefonia em atividade no Brasil, se sujeita a insolência que alcança dimensões inimagináveis, causando dissabores ao consumidor. Diversas práticas abusivas e gananciosas por lucro, têm causado grandes transtornos aos brasileiros, muitos deles dispondo de seus direitos por ausência de tempo ou de informação. Essa vulnerabilidade tem proporcionado sensação de impunidade em detrimento da sociedade, que não tem o amparo legal suficiente da ANATEL.

O presente artigo objetiva analisar, de forma sucinta, as práticas abusivas das operadoras de telefonia em exercício no Brasil, considerando-se a complexidade do assunto no tocante à evolução tecnológica veloz, e a necessidade de acompanhamento do ordenamento jurídico na mesma proporção.

\section{METODOLOGIA}

Para cumprir o objetivo proposto, o estudo seguirá os métodos dialético-dedutivo, com emprego de pesquisa à legislação, doutrina e jurisprudência acerca da matéria objeto do estudo, bem como a artigos informativos sobre o tema.

\section{RESULTADOS}

Os resultados do presente estudo evidenciaram a necessidade de obtenção de uma maior clareza na legislação brasileira no tocante à franquia diária de uso de dados (Internet), tanto na modalidade fixa como na móvel, por meio de normas que esclareçam o consumidor e limitem a voracidade das empresas por lucro astronômico, necessidade essa combinada com providências mais rigorosas das autoridades competentes a respeito da insolência das operadoras de telefonia.

\section{O MODO DE ATUAÇÃO DAS OPERADORAS}

O celular tornou-se a ferramenta de trabalho e entretenimento mais importante e utilizado pelos brasileiros e provavelmente por toda a humanidade, desde o simples ato de se comunicar, até as primordiais funções, como relógio, despertador, agenda, redes sociais e aplicativos de mensagens instantâneas e vídeo chamadas. O objetivo para tantos recursos justifica-se em saber se há alguma mensagem ou notificação que exija resposta imediata ou o mais breve possível, não podendo se esquecer do envio de atividades estudantis. Indubitavelmente, o telefone celular deixou de ser um simples aparelho telefônico (Poisler, 2015).

Porém, prosseguindo o raciocínio, junto com a tecnologia, vêm os aborrecimentos, como, por exemplo, a interrupção repentina da Internet, levando o consumidor a suspeitar de uma pequena falha de conexão que será contornada em instantes, o que não ocorre. Somente percebe que existe algo errado em sua linha, quando constata um baixo saldo de créditos que se desvia do planejamento de despesas para tal, mesmo após adquirir forçadamente um pacote de, por exemplo, 100MB, por estar insatisfeito pelo bloqueio da conexão, sem ao menos haver uma norma estabelecida pela Anatel a respeito.

Na ausência de conexão da operadora, existem outras alternativas como as zonas wi-fi em ambientes públicos, ou, simplesmente, em suas residências, ou passar o dia se sentindo como um náufrago, na esperança de ter contato com o mundo através da conexão wi-fi em algum espaço público. A situação se torna emergencial quando o saldo de créditos é considerado escasso. Atualmente, com $\mathrm{R} \$ 1.65$, por exemplo, é possível usar ao menos $\mathrm{R} \$ 50 \mathrm{MB}$ por $\mathrm{R} \$ 0,99$, ofertados pela operadora de telefonia Tim (Tim Brasil, 2016). Mas para surpresa, ao tentar ansiosamente por esse salvamento, o consumidor recebe a resposta de que "não é elegível para a oferta", mesmo dotado de saldo suficiente e pagar apenas por dia que usar. Se este sofre alguma perda pelo não cumprimento de algum afazer, certamente se sente prejudicado pela empresa. 
Não singularmente, com o ritmo acelerado do dia, farto de tarefas a fazer, assim que possível, a solução é acessar o detalhamento do consumo no site da operadora, através da wi-fi residencial, e eis então que surpresas aparecem, como por exemplo, serviços sem solicitação ou autorização, e ainda, descontos de promoções concorrendo a prêmios, cuja participação foi anunciada como gratuita, porém com a recusa de uma assinatura para prosseguir. Em nenhum momento, esse consumidor, não acostumado a participar de promoções, foi orientado sobre como proceder para não mais participar, raciocinando o próprio, pela possibilidade de enviar a palavra "SAIR" para deixar de utilizar o serviço indesejado. Esse é o perfil de um consumidor lesado pela insolência de sua operadora de telefonia.

Tal lesão é uma das espécies de vício de serviço, previstas no Código de Defesa do Consumidor, como também ensina Venosa (2009, p. 243):

Assim como em relação ao produto, o serviço defeituoso deve ser examinado no momento em que é prestado. O serviço é defeituoso quando não fornece segurança para o consumidor. Os defeitos de serviço podem decorrer de concepção ou de execução indevidas. (SIC)

A primeira providência acertada por muitos consumidores, é dar screen (fotografar a imagem da tela) das provas, e imprimi-las, para, imediatamente, anexá-las em uma reclamação no Procon. Se tiver tempo livre para isso, considera-se sorte. Caso negativo, torna-se mais difícil reclamar seus direitos.

Analisando juridicamente tais práticas descritas em forma de situação cotidiana, vale lembrar o que estabelece os artigos 20 e 29 do Código de Defesa do Consumidor (Brasil, 1990), sobre a coletividade de consumidores que recebem essas ofertas. A coletividade de pessoas ainda que indetermináveis, envolvidas na relação de consumo, são equiparadas a consumidor, bem como todas as pessoas determináveis ou não, expostas às praticas previstas em tal código.

$\mathrm{O}$ art. 4으, inciso I da mesma norma, reconhece a vulnerabilidade do consumidor no mercado de consumo. Entre os direitos básicos do consumidor previstos no artigo 60, incisos IV e $\mathrm{X}$, combinado com o art. 22 do CDC, observa-se a proteção contra a publicidade enganosa e abusiva, métodos comerciais coercitivos ou desleais, bem como práticas e cláusulas abusivas visando o fornecimento de produtos e serviços, garantindo a adequada e eficaz prestação dos serviços públicos em geral, e a obrigatoriedade das operadoras em fornecer serviços adequados, eficientes, seguros e, quanto aos essenciais, contínuos.

\section{ANALISANDO CADA UMA DAS PRÁTICAS INSOLENTES AS PROMOÇÕES CONCORRENDO A AUTOMÓVEIS}

Raramente, o usuário descobre que os descontos não eram referentes à promoção, e sim, que a lesão ocorre há mais tempo. Mas hipoteticamente, se não descobre ou se realmente são relativos à promoção, se prometeu que a participação é gratuita, tem que cumprir. O amparo legal encontra-se no art. 30 do CDC (Brasil, 1990), que determina que a informação ou publicidade com relação a produtos e serviços oferecidos ou apresentados devem ser claros e precisos, obrigando o fornecedor a cumprir conforme anunciado. Caso o Procon repasse a resposta dada de que não poderá devolver o dinheiro, pois trata-se de uma promoção de uma empresa representando a operadora, mister se faz observar os arts. 34, 35 e 51 do mesmo código (Brasil, 1990). Há previsão de responsabilidade solidária do fornecedor do produto ou serviço pelos atos de empresas que o representam.

Observando os artigos citados acima, na recusa de cumprimento à oferta, apresentação ou publicidade, o consumidor poderá escolher alternativamente: exigir o cumprimento forçado da oferta conforme anunciada; aceitar outro produto ou prestação de serviço equivalente, ou; rescindir o contrato com direito à restituição (reembolso) da quantia eventualmente paga de forma antecipada, com direito à correção monetária e perdas e danos. É preciso frisar que é 
considerada nula a cláusula que isenta o fornecedor quanto à opção de reembolso da quantia já paga. Mesmo que tenha sido apenas uma oferta, não deixa de ser um contrato, pois se trata de um combinado entre a operadora e o consumidor (Brasil, 1990).

Se o consumidor reclama seus direitos junto ao Procon, a solução imediata é a restituição do valor. No caso das operadoras de telefonia, essas efetuam recargas no valor a ser restituído, como forma de ressarcir o valor subtraído de forma lesiva.

\section{AS OFERTAS CAMUFLADAS EM NOTIFICAÇÕES OFERTAS DE PACOTES DE BACKUP}

Ultimamente, tem sido comum receber ofertas ou outras formas de publicidade disfarçadas em notificações que não sejam por SMS, de modo que o consumidor facilmente não as reconheçam como tais, e acabe aderindo às mesmas ao esbarrar, sem querer, no botão errado num simples gesto de desbloqueio de celular ou acesso a um aplicativo. Em contradição, não é o que estabelece o art. 36 do CDC (Brasil, 1990).

Tais notificações caracterizam a chamada "publicidade mascarada", segundo Tartuce (2014, p. 263):

Trata-se da vedação, por ilicitude, da publicidade mascarada, tida também com publicidade simulada ou dissimulada. É aquela transmissão de informações que parece que não é publicidade, mas é publicidade. Pode ser feito um paralelo com a simulação, vício social típico do Direito Civil (art. 167 do CC/2002), pois, nos dois casos, há uma discrepância entre a vontade interna e a vontade manifestada, isto é, entre aparência e essência. (SIC)

Tal espécie de publicidade é conceituada também como "publicidade simulada", como ensina Coelho (2007, p. 103), que faz uma semelhança com os conceitos de publicidade e propaganda:

"Publicidade simulada é a que procura ocultar o seu caráter de propaganda" [...]"São exemplos de publicidade simulada a inserção, em jornais e periódicos, de propaganda com aparência externa de reportagem, ou a subliminar, captável pelo inconsciente, mas imperceptível ao consciente". (SIC)

Analisando de forma prática, o que a oferta de backup e outras promoções disfarçadas de notificação têm em comum, é sua oferta de forma enganosa, descrita no art. 37, parágrafos 10 e 3o do CDC (Brasil, 1990), que proíbe a publicidade enganosa ou abusiva, descrevendo como enganosa a publicidade inteira ou parcialmente falsa, por qualquer modo capaz, mesmo por omissão, de induzir em erro o consumidor quanto aos detalhes dessa publicidade. Descreve como publicidade enganosa se a omissão deixar de informar algo essencial a respeito do produto ou serviço. A respeito da veracidade e do disfarce das informações, o assunto encontra maior suporte doutrinário a ser abordado mais adiante.

\section{A IMPOSSIBILIDADE DE MUDANÇA DE PLANO DE FRANQUIA DE DADOS OU INTERNET}

No tocante à tentativa sem sucesso de migrar para outro plano de franquia, principalmente inferior ao atual, o direito tolhido encontra respaldo no art. 39, inciso IX, do Código de Defesa do Consumidor (Brasil, 1990), que veda ao fornecedor recusar a venda de bens ou a prestação de serviços ao consumidor que tiver condições de adquiri-los mediante pronto pagamento, ressalvando os casos de intermediação regulados em leis especiais.

\section{A MÁ-FÉ COM A INSOLÊNCIA DAS OPERADORAS}


A publicidade enganosa tem o dolo como elemento essencial para sua caracterização, pois induz o consumidor a atender aos desejos do prestador de serviços, ou seja, a aquisição de algo que não pretendia ou desejava. Ensina, mais uma vez, e complementa Tartuce (2014, p. 264):

Apesar da menção ao engano, ao erro, não se pode esquecer que o ato de indução representa dolo, ou seja, uma atuação maliciosa praticada com intuito de enganar outrem e ter benefício próprio. Então, o paralelo deve ser feito, em diálogo das fontes, em relação ao tratamento desse vício do consentimento, tratado entre os arts. 145 a 150 do CC/2002. (SIC)

É evidente e notório que as operadoras se aproveitam da vulnerabilidade do consumidor. Considera-se uma exceção se, por sorte, esse consegue se programar para ir ao Procon e reclamar por seus direitos sem prejudicar sua rotina. Opostamente, muitos, na prática, não contam com essa possibilidade devido aos diversos afazeres. Com isso, as operadoras lucram à custa daqueles que não reclamam por desinteresse ou por falta de tempo para isso. (Poisler, 2015).

A voracidade por lucro astronômico é severamente punida pela legislação vigente. $O$ art. 55, §4으 do CDC (Brasil, 1990), prevê notificações aos fornecedores para que prestem informações sob pena de desobediência, resguardado o segredo industrial também protegido por lei, este muito estudado especialmente no Direito Empresarial. Já o art. 56, incluindo os incisos I, VI e XII do CDC, estabelece penalidades como multa, suspensão de fornecimento de produtos ou serviço e imposição de contrapropaganda (Brasil, 1990).

Sobre a contrapropaganda, com imposição prevista no art. 60 do mesmo código (Brasil, 1990), a forma a ser realizada será na mesma forma, frequência e dimensão que fez a publicidade enganosa ou abusiva, com a finalidade de desfazer o malefício, e as despesas serão por conta do infrator.

\section{POSICIONAMENTOS DOUTRINÁRIOS E JURISPRUDENCIAIS}

O Ministro do STJ e doutrinador Herman Benjamin (2008, p. 4) afirma em seu voto ao julgar caso semelhante:

As concessionárias de telefonia são, para todos os fins, fornecedoras, e as suas prestações de serviço aos assinantes-usuários caracterizam relação jurídica de consumo, nos termos do Código de Defesa do Consumidor CDC. Os objetivos, princípios, direitos e obrigações previstos no CDC aplicam-se integralmente aos serviços de telefonia, fixa ou não. (SIC)

A publicidade enganosa não é uma prática apenas dos tempos atuais, conforme Martins (2009, p. 190 a 193, passim):

A publicidade enganosa é uma rotina praticada livremente no mercado de telefonia celular. Em Minas Gerais, o Ministério Público chegou a ajuizar Ação Coletiva com o objetivo de repelir Uma das práticas também rotineiras efetivadas pelas operadoras de telefonia celular envolve o envio de mensagens não solicitadas para celulares, que o consumidor paga quando tem que acessar sua caixa postal para ouvi-las, ou mesmo publicidades veiculadas ao consumidor que aguarda na linha telefônica o atendimento de suas solicitações, sendo prática vedada pelo art. 33, parágrafo único do CDC. (SIC)

As práticas abusivas têm sido severamente rebatidas, conforme o mesmo periódico:

Estabelece o art. 51, IV do CDC que são nulas de pleno direito as cláusulas que estabeleçam obrigações consideradas iníquas, abusivas, que coloquem o consumidor em desvantagem exagerada, ou que sejam incompatíveis 
com a boa-fé ou a equidade. Logo, a cláusula contratual que ofende o princípio da boa-fé objetiva é considerada nula, pois o consumidor teve a sua expectativa frustrada, pelo abuso da confiança por ele depositada. (SIC)

Apesar da distinção entre propaganda e publicidade, o consumidor é, igualmente, ludibriado pela imagem transmitida, seja por meio de propaganda ou de publicidade, embora, de acordo com Rizzato (2012), a Constituição Federal não faça distinção entre ambos os termos, que complementa a respeito da veracidade da divulgação:

Tomado pela etiologia, vê-se que o termo "propaganda" tem origem no latim "propaganda, do gerundivo de 'propagare', 'coisas que devem ser propagadas". Donde afirmar-se que a palavra comporta o sentido de propagação de princípios, ideias, conhecimentos ou teorias. O vocábulo "publicidade", por sua vez, aponta para a qualidade daquilo que é público ou do que é feito em público. Ambos os termos, portanto, seriam bastante adequados para expressar o sentido buscado pelo anunciante de produto ou serviço. [...] Assim, tanto no art. 37 quanto no capítulo da comunicação social a Carta Magna protege a ética. E para fins de publicidade em matéria de relações de consumo, o valor ético fundamental é o da verdade. 0 anúncio publicitário não pode faltar com a verdade daquilo que anuncia, de forma alguma, quer seja por afirmação quer por omissão. Nem mesmo manipulando frases, sons e imagens para, de maneira confusa ou ambígua, iludir o destinatário do anúncio. (SIC)

A manipulação de frases, sons e imagens citada pelo autor, pode ser facilmente estendida, por analogia, à publicidade ou propaganda enviada pelas operadoras aos consumidores, disfarçadamente por meio de notificações que não sejam os padrões SMS, popularmente conhecidos como "torpedos".

\section{CONCLUSÃO:}

O presente artigo objetivou analisar, de forma sucinta, as práticas abusivas das operadoras de telefonia em exercício no Brasil, considerando-se a complexidade do assunto no tocante à evolução tecnológica veloz, e a necessidade de acompanhamento do ordenamento jurídico na mesma proporção.

Constatou-se que a justiça tem decidido com rigor os casos envolvendo tais prestadoras de serviços, porém, tais decisões parecem não punir suficientemente as mesmas, tendo em vista a continuidade da insolência.

Notou-se que, apesar do Código de Defesa do Consumidor e outros meios jurídicos guiarem e resolverem situações atuais, a Agência Nacional de Telecomunicações - ANATEL precisa por fim à obscuridade normativa a respeito da franquia diária de uso de dados (Internet), publicando um decreto ou norma semelhante que esclareça o consumidor e limite a voracidade das empresas por lucro astronômico.

Diante da insolência das operadoras de telefonia em exercício no Brasil, embora haja previsão de inversão do ônus da prova no Código de Defesa do Consumidor, os usuários precisam ter meios defensivos para melhor buscarem seus direitos. Em outras palavras, mesmo que a obrigação de provar a veracidade ou a inveracidade dos fatos seja das operadoras, se o consumidor tiver consigo provas necessárias e relevantes, as chances de ter seu direito obtido e satisfeito são muito maiores.

As táticas defensivas apropriadas ao consumidor em tais casos, se adotadas, facilitam na busca pelo direito tolhido, como por exemplo, armazenar todas as mensagens SMS das promoções das quais participar; mesmo que o Código de Defesa do Consumidor estabeleça a chamada 
"inversão do ônus da prova" no art. 6으, inciso VIII (Brasil, 1990), que determina que a operadora é quem deve provar que o fato não ocorreu da maneira que o consumidor alega, é uma atitude de cautela gravar a imagem da tela e imprimir o máximo de provas possíveis de que foi lesado; se o consumidor paga caro considerando sua renda mensal, não deve deixar de encaminhar ao Procon, junto com as provas, uma cópia da folha de pagamento (holerite), com o objetivo de mostrar que seu salário não é abundante, e que o prejuízo sofrido desnecessariamente, equivale a determinados dias de seu trabalho que dedicou para adquirir tais créditos subtraídos indevidamente.

Resulta claro que a precaução é a melhor solução, e a iniciativa de pleitear o direito tolhido serve como uma espécie de freio à insolência das operadoras de telefonia. Portanto, o consumidor deve buscar seus direitos e lutar por eles. Caso contrário, as operadoras de telefonia, com sua insolência, continuarão a lesar os consumidores de todo o Brasil.

\section{REFERÊNCIAS BIBLIOGRÁFICAS}

BRASIL. // Superior Tribunal de Justiça. // Voto-vencido. // Recurso Especial no 1.006.892 - MG (2007/0271242-4). // Recorrente: Telemar Norte Leste LTDA. Recorrido: Carmo Luiz Neves de Lima. // Relatora Ministra Eliana Calmon. // Brasília, 04 de março de 2008. // Disponível em: $<$ https://ww2.stj.jus.br/processo/revista/documento/mediado/?componente=ATC\&sequencial=4 401648\&num registro $=200702712424 \&$ data $=20081117 \&$ tipo $=52 \&$ formato $=P D F>$. // Acesso em: 16 jul. 2016.

BRASIL. Lei $\mathrm{n}$ 0 8.078, de 11 de setembro de 1990. // Código de Defesa do Consumidor. Disponível em: <http://www.planalto.gov.br/ccivil 03/Leis/L8078.htm>.//Acesso em: 16 jul. 2016.

COELHO, Fábio U1hoa. Manual de Direito Comercial. Direito de Empresa. 18. ed. São Paulo: Saraiva, 2007. p. 103.

MARTINS, Plinio Lacerda. A Proteção do Consumidor nos Contratos de Telefonia Móvel e Fixa e a Interpretação Jurisprudencial. REVISTA EMERJ, v. 12, no 48, 2009, p. 190 a 191, e 193. Disponível em: <http://www.emeri.ri.gov.br/revistaemerj online/edicoes/revista48/Revista48 175.pdf>. Acesso em 16 de jul. de 2016.

NUNES, Luis Antonio Rizzatto. Curso de direito do consumidor / Rizzatto Nunes. 7. ed. rev. e atual. São Paulo: Saraiva, 2012, p. 109-111.

TIM BRASIL. Infinity Web - Diário Web Dia. Tim Celular S/A. Disponível em <http://www.tim.com.br/ri/para-voce/planos/pre-pago/sumarios/adicionais-infinity-webtorpedo> Acesso em 07 ago. 2016.

POISLER, Erica Da Silva. A Insolência das Operadoras de Telefonia. Crônica Jurídica eletrônica com adaptações. Disponível em: <https://www.facebook.com/photo.php?fbid=900150930048897\&l=21e5f29755> Adaptado e acessado em: 07 ago. 2016.

VENOSA, Sílvio de Salvo. Direito Civil. Responsabilidade Civil. Nova edição. Volume 4. Editora Atlas: São Paulo. 2009. Página 243.

TARTUCE, Flávio. Manual de direito do consumidor: direito material e processual / Flávio Tartuce, Daniel Amorim Assumpção Neves. 3. ed. Rio de Janeiro: Forense: São Paulo: Método, 2014, p. 263264. 